सू. ACS Publications

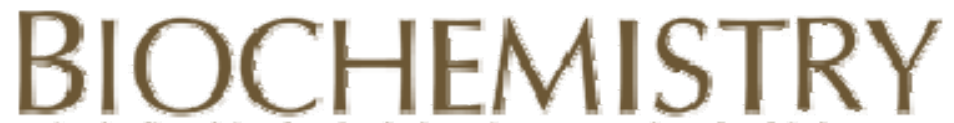

including biophysical chemistry \& molecular biology

http://pubs.acs.org/doi/abs/10.1021/bi201195u 


\section{Trolox, a water soluble analogue of alpha-tocopherol, photoprotects the surface-exposed regions of the photosystem II reaction centre in vitro. Is this physiologically relevant?}

\begin{tabular}{|c|c|}
\hline Journal: & Biochemistry \\
\hline Manuscript ID: & bi-2011-01195u.R1 \\
\hline Manuscript Type: & Article \\
\hline $\begin{array}{r}\text { Date Submitted by the } \\
\text { Author: }\end{array}$ & $\mathrm{n} / \mathrm{a}$ \\
\hline Complete List of Authors: & $\begin{array}{l}\text { Arellano, Juan; Instituto de Recursos Naturales y Agrobiología de } \\
\text { Salamanca (IRNASA-CSIC), Estrés Abiótico } \\
\text { Li, Heng; Norwegian University of Science and Technology, } \\
\text { Department of Physics } \\
\text { González-Pérez, Sergio; Instituto de Recursos Naturales y } \\
\text { Agrobiología de Salamanca (IRNASA-CSIC), Estrés abiótico } \\
\text { Gutiérrez, Jorge; Instituto de Recursos Naturales y Agrobiología de } \\
\text { Salamanca (IRNASA-CSIC), Estrés abiótico } \\
\text { Melo, Thor; Norwegian University of Science and Technology, } \\
\text { Department of Physics } \\
\text { Vacha, Frantisek; Biology Centre, Academy of Sciences of the Czech } \\
\text { Republic } \\
\text { Naqvi, K. Razi; NTNU }\end{array}$ \\
\hline
\end{tabular}

\section{SCHOLARONE Manuscripts}


Trolox, a water soluble analogue of $\alpha$-tocopherol, photoprotects the surfaceexposed regions of the photosystem II reaction centre in vitro. Is this physiologically relevant? ${ }^{\dagger}$

\begin{abstract}
${ }^{\dagger}$ This work was funded by the Research Council of Norway (Project No. 191102) and the Spanish Ministry of Science and Innovation (Grant number BFU2007-68107-C0202/BMC). JBA is very grateful to the CSIC mobility programme for funding his short term visit to NTNU (Ref. number PA1002668).
\end{abstract}

\author{
Juan B. Arellano ${ }^{\ddagger},{ }^{*}$, Heng Li ${ }^{\S}$, Sergio González-Pérez ${ }^{\ddagger}$, Jorge Gutiérrez ${ }^{\ddagger}$, Thor Bernt \\ Melø ${ }^{\S}$, Frantisek Vacha" ${ }^{\prime}$, K. Razi Naqvi ${ }^{\S, *}$ \\ ${ }^{\ddagger}$ Instituto de Recursos Naturales y Agrobiología de Salamanca (IRNASA-CSIC), Apdo. \\ 257, 37071 Salamanca, Spain \\ $\S$ Department of Physics, Norwegian University of Science and Technology. N-7491 \\ Trondheim (Norway) \\ "| Biology Centre, Academy of Sciences of the Czech Republic, Branišovská 31, 37005 \\ České Budějovice, Czech Republic
}

Corresponding authors: K. Razi Naqvi, E-mail address: razi.naqvi@ntnu.no; Tel.: +47 7359 1853; Fax: +47 7359 7710, Juan B. Arellano, E-mail address: juan.arellano@irnasa.csic.es; Tel.: +34 923219 606; Fax: + 34923219609. 


\begin{abstract}
Abbreviations: $\beta$-Car, $\beta$-carotene; Chl, chlorophyll; $\mathrm{Chl}_{\mathrm{D} 1}$, accessory $\mathrm{Chl}$ in the $\mathrm{D} 1$ protein; DAB, 3,3'-diaminobenzidine tetrahydrochloride; DM, $n$-dodecyl $\beta$-Dmaltoside; DNPH, 2,4-dinitrophenylhydrazine; LD, linear dichroism; MB, Methylene blue; ${ }^{3} \mathrm{P}$, total population of $\mathrm{Chl}$ triplets in PSII RC (i.e., ${ }^{3} \mathrm{Chl} \mathrm{D}_{\mathrm{D}}$ and ${ }^{3} \mathrm{P}_{680}$ in thermal equilibrium); $\mathrm{P}_{680}$, primary donor of PSII; Phe, pheophytin; PSII, photosystem II; RC, reaction centre; RC5, five-chlorophyll PSII RC; RC6, standard RC containing six chlorophyll molecules; ROS, reactive oxygen species; Trolox, 6-hydroxy-2,5,7,8tetramethylchromane-2-carboxylic acid
\end{abstract}




\section{Abstract}

Can Trolox, a water soluble analogue of $\alpha$-tocopherol and a scavenger of singlet oxygen $\left({ }^{1} \mathrm{O}_{2}\right)$, provide photoprotection, under high irradiance, to isolated photosystem II (PSII) reaction centre (RC)? To answer the question, endogenous production of ${ }^{1} \mathrm{O}_{2}$ was studied in preparations of five-chlorophyll PSII RC (RC5) containing only one $\beta$ carotene molecule. The temporal profile of ${ }^{1} \mathrm{O}_{2}$ emission at $1270 \mathrm{~nm}$ photogenerated by $\mathrm{RC} 5$ in $\mathrm{D}_{2} \mathrm{O}$ followed the expected biexponential behaviour, with a rise time, unaffected by Trolox, of $13 \pm 1 \mu$ s, and a decay time of $54 \pm 2 \mu$ s (without Trolox) and $38 \pm 2 \mu$ s in the presence of $25 \mu \mathrm{M}$ Trolox. The ratio between the total $\left(k_{\mathrm{t}}\right)$ and chemical $\left(k_{\mathrm{r}}\right)$ bimolecular rate constants for the scavenging of ${ }^{1} \mathrm{O}_{2}$ by Trolox in aqueous buffer was calculated to be $\sim 1.3$, with $k_{\mathrm{t}}=(2.4 \pm 0.2) \times 10^{8} \mathrm{M}^{-1} \mathrm{~s}^{-1}$ and $k_{\mathrm{r}}=(1.8 \pm 0.2) \times 10^{8} \mathrm{M}^{-1} \mathrm{~s}^{-1}$, indicating that most of the ${ }^{1} \mathrm{O}_{2}$ photosensitized by methylene blue chemically reacts with Trolox in the assay buffer. The photoinduced oxygen consumption in the oxygen electrode, when RC5 and Trolox were mixed, revealed that Trolox was a better ${ }^{1} \mathrm{O}_{2}$ scavenger than histidine and furfuryl alcohol at low concentrations (i.e., $<1 \mathrm{mM})$. After its incorporation into detergent micelles in unbuffered solutions, Trolox was able to photoprotect the surface-exposed regions of the heterodimer D1/D2, but not the RC5 pigments, which were oxidized, together with the membrane region of the protein matrix of PSII RC, by ${ }^{1} \mathrm{O}_{2}$. These results are discussed and compared with studies dealing with the physiological role of tocopherol molecules as ${ }^{1} \mathrm{O}_{2}$ scavenger in thylakoid membranes of photosynthetic organisms. 
Singlet oxygen $\left({ }^{1} \mathrm{O}_{2}\right)$, the dioxygen molecule in its lowest excited electronic state, is characterized by its high reactivity towards biological systems (1-3). In photosynthetic organisms, ${ }^{1} \mathrm{O}_{2}$ is generated during an encounter between a ground state dioxygen molecule and a chlorophyll (Chl) molecule in its triplet excited state (4). The yield of ${ }^{1} \mathrm{O}_{2}$ formation is particularly high in the reaction centre (RC) of photosystem II (PSII), where the donor triplet is produced through the radical pair mechanism, which comes into play when electron transfer on its acceptor side is inhibited, or the plastoquinones, denoted $\mathrm{Q}_{\mathrm{A}}$ and $\mathrm{Q}_{\mathrm{B}}$, are removed or doubly reduced (5-7). Chl triplets produced by intersystem crossing in the antenna complexes of PSII can also cause the photodamage of PSII (8).

PSII RC from higher plants was the first biological system in which direct emission at $1270 \mathrm{~nm}$ from ${ }^{1} \mathrm{O}_{2}$ with an endogenous origin was observed (9). The pigment arrangement in the PSII RC imposed by the protein matrix of the heterodimer $\mathrm{D} 1 / \mathrm{D} 2(10)$ is unfavourable for efficient triplet-triplet energy transfer from ${ }^{3} \mathrm{P}$ to $\beta$-Car (7), since the two $\beta$-carotene ( $\beta$-Car) molecules are far from the accessory Chl molecule in the $\mathrm{D} 1$ protein $\left(\mathrm{Chl}_{\mathrm{D} 1}\right)$ where the triplet population is mainly localized, and only a minor population is in the primary donor $\mathrm{P}_{680}$, denoted $\mathrm{P}_{\mathrm{D} 1}$ and $\mathrm{P}_{\mathrm{D} 2}(11)$. Hereafter, ${ }^{3} \mathrm{P}$ represents the total population of Chl triplets in PSII RC (i.e., ${ }^{3} \mathrm{Chl}_{\mathrm{D} 1}$ and ${ }^{3} \mathrm{P}_{680}$ in thermal equilibrium). The two $\beta$-Car molecules only play a marginal photoprotective role against ${ }^{1} \mathrm{O}_{2}$ within PSII RC, and the pigments and the D1 protein of PSII RC remain very vulnerable when photosensitation of ${ }^{1} \mathrm{O}_{2}$ by ${ }^{3} \mathrm{P}$ takes place (12).

Over the last decade, efforts have been made to gain a better understanding of alternative photoprotective mechanisms, mediated by other types of molecules capable of scavenging ${ }^{1} \mathrm{O}_{2}$ more efficiently in PSII. In a series of papers, Trebst and co-workers 
proposed that tocopherol molecules must be the scavenger of ${ }^{1} \mathrm{O}_{2}$ photosensitized in PSII. Using the herbicide pyrazolynate, an inhibitor of the 4-hydroxyphenylpyruvate dioxygenase belonging to the biosynthetic pathway of tocopherol (and also plastoquinone), they observed a decrease, when the cells were subjected to high light stress for $2 \mathrm{~h}$, in the tocopherol content in Chlamydomonas reinhardtii and a concomitant loss of the D1 protein in PSII $(13,14)$. These results received support from experiments, conducted by other researchers (15), involving the double mutant vte1 npql of Arabidopsis thaliana, which is deficient in the biosynthesis of both tocopherol and zeaxanthin; nearly half of the D1 protein was lost when the plants were exposed to high light at low temperatures. Plastoquinol molecules have also been proposed to play a role in the photoprotection of PSII through scavenging of ${ }^{1} \mathrm{O}_{2}(16-18)$. The above studies, carried out with Chlamydomonas cells, showed that tocopherol and plastoquinone biosynthesis exhibited a fast turnover rate at high light as a direct consequence of the larger production of ${ }^{1} \mathrm{O}_{2}(13,16)$. Recently, it has been demonstrated that the deficiency of $\alpha$-tocopherol in mutants of Arabidopsis thaliana (vte1) and Synechocystis sp. PCC6803 (slr0090) enhances the susceptibility of PSII to photoinhibition because the repair cycle of the photodamaged PSII is inhibited, not because the rate of photoinactivation of PSII is affected $(19,20)$.

In this study, we have used Trolox (6-hydroxy-2,5,7,8-tetramethylchromane-2carboxylic acid), a water soluble analogue of $\alpha$-tocopherol, as a scavenger of ${ }^{1} \mathrm{O}_{2}$, to determine whether it can play a role in the photoprotection of PSII in vitro, similar to that of tocopherol molecules in vivo. The use of Trolox brings several advantages. First, short-chain $\alpha$-tocopherol analogues, in particular those with $1 \mathrm{C}$, are in a monomeric form in membranes and exhibit both high mobility and high scavenging activity in contrast to $\alpha$-tocopherol with a chain length of $16 \mathrm{C}$, which, in fact, has very limited 
mobility and forms clusters in membranes $(21,22)$. Second, Trolox has two dissociable protons, with $\mathrm{p} K$ values of 3.89 for the carboxylic group and 11.92 for the hydroxyl group (also present in $\alpha$-tocopherol) $(23,24)$, which affect its solubility in aqueous media. Based on these dissociation constants, Trolox can be easily dissolved in neutral and basic pH-adjusted solutions, or it can be solubilized in detergent micelles in unbuffered aqueous media (25). Third, although the total bimolecular rate constant for the scavenging of ${ }^{1} \mathrm{O}_{2}$ by Trolox is known to be about half of that for $\alpha$-tocopherol (25, 26), the use of Trolox in this study has enabled us to determine the ratio between the total and chemical bimolecular rate constants for the scavenging of ${ }^{1} \mathrm{O}_{2}$ in aqueous buffer, where PSII RC and Trolox are dispersed homogenously. PSII RC (instead of PSII) preparations are used here to facilitate the accessibility of Trolox to the D1 protein and the pigments housed inside the PSII RC protein matrix. Our results clearly show that Trolox can photoprotect the surface-exposed regions of the heterodimer D1/D2 from photodamage only when Trolox is in the detergent micelles close to PSII RC, but not when it is freely dissolved in the buffer. This photoprotection requires a high consumption of Trolox. Although Trolox succeeds in photoprotecting the surfaceexposed domain of the heterodimer D1/D2, the PSII RC pigments and the membrane region of the protein matrix of PSII RC are left vulnerable to ${ }^{1} \mathrm{O}_{2}$ in the situations examined here. The relevance of this photoprotection mechanism is discussed and compared with the physiological role that tocopherol molecules play in the scavenging of ${ }^{1} \mathrm{O}_{2}$ in thylakoid membranes.

\section{Material and methods}

\section{Chemicals}


Trolox, L-histidine, furfuryl alcohol (2-hydroxymethyl-furan) and sodium azide $\left(\mathrm{NaN}_{3}\right)$ were purchased from Sigma-Aldrich (St. Louis, MO) and used with no further purification.

\section{Isolation of PSII RC's}

The isolation of five-Chl RC (RC5) of PSII from 4-week-old pea plants (Pisum sativum L var. Lincoln) was performed following the procedure described in reference (27) with minor modifications (28). The isolation of standard RC (RC6) containing a stoichiometric ratio of $6 \mathrm{Chl}$ molecules and $2 \beta$-Car molecules per 2 pheophytin (Phe) molecules was done using the method of Chapman et al. (29) with the sole purpose of comparing the linear dichroism (LD) spectra of RC5 and RC6. Samples of RC5 were kept in $50 \mathrm{mM}$ Tris- $\mathrm{HCl}, 0.01 \%(\mathrm{w} / \mathrm{v}) n$-dodecyl $\beta$-D-maltoside (DM) pH 7.2 (assay buffer) at $-80^{\circ} \mathrm{C}$ until use.

\section{Linear dichroism}

LD was measured using a Jasco-715 spectropolarimetre (Jasco, Japan) equipped with a temperature-controlled cryostat Optistat Bath (Oxford Instruments, UK). Samples of PSII RC with an absorbance at $675 \mathrm{~nm}$ (for an optical path of $1 \mathrm{~cm}$ ) of $\sim 1$ were polymerised in a $10 \%(\mathrm{w} / \mathrm{v})$ polyacrylamide gel containing $50 \mathrm{mM}$ Tris- $\mathrm{HCl} \mathrm{pH}$ 7.5 and $60 \%$ (v/v) glycerol. The PSII RC samples were polymerised within a block and then squeezed in two perpendicular axes using a compression factor of 0.83 . The compression factor was calculated as the ratio between the original and final dimension 
in one of the compressed directions. The compression, which had no effect on the isotropic absorption spectrum of PSII RC, resulted in creating a partially oriented sample in which the membrane plane are preferentially aligned perpendicular to the direction of compression (that is, parallel to the direction of the gel expansion); this creates a system with uniaxial symmetry around the direction of compression (to be called the director). The absorption anisotropy, defined as the ratio $\rho=\Delta A / A_{\text {iso }}$, provides a measure of the orientational distribution of the transition dipoles around the director; here $\Delta A \equiv A_{\|}-A_{\perp}$ and $A_{\text {iso }}=\left(A_{\|}+2 A_{\perp}\right) / 3$, whereas $A_{\|}$and $A_{\perp}$ denote the absorbance recorded by using linearly polarized beams with electric vectors oriented, respectively, parallel (II) and perpendicular $(\perp)$ to the director. If $\theta$ denotes the angle between a transition dipole and the director, one can write $\rho=\left(3 \overline{\cos ^{2} \theta}-1\right) / 2$, where the overline denotes an average over all the transition dipoles, which shows that $1 \leq \rho \leq-1 / 2$. The limiting value $\rho=1$ corresponds to perfect alignment with respect to the director and $\rho=-1 / 2$ arises when all dipoles lie randomly in a plane perpendicular to the director. A positive value of $\rho$ reflects, therefore, a preferential alignment towards the director. When the foregoing considerations are applied to photosynthetic systems oriented by the polyacrylamide gel squeezing technique, it is customary (30) to define $A_{\|}$and $A_{\perp}$ as the absorbances measured with light polarized parallel and perpendicular, respectively, to the longer axis of the oriented object (that is, perpendicular to the director) and, for the sake of convenience, one measures only $\Delta A \equiv A_{\|}-A_{\perp}$. Since this convention, which will be followed here, interchanges $A_{\|}$ and $A_{\perp}$ as defined above, negative values of $\Delta A \equiv A_{\|}-A_{\perp}$ are to be interpreted as a preferential orientation of the transition dipoles towards the direction of compression. 
Oxygen consumption

Oxygen consumption by scavengers of ${ }^{1} \mathrm{O}_{2}$ was measured polarographically using a Chlorolab 2 system (Hansatech Instruments, Norfolk England) at $20^{\circ} \mathrm{C}$. Samples were incubated in dark for $1 \mathrm{~min}$ before switching on the light emitting diode source. The light irradiance in the electrode chamber was $2 \mathrm{mE} \mathrm{cm}^{-2} \mathrm{~s}^{-1}$. Methylene blue (MB) and RC5 were used as photosensitizers of ${ }^{1} \mathrm{O}_{2}$. For each experiment, the absorbance of the photosensitizer is indicated in the figure legends.

Time-resolved ${ }^{1} \mathrm{O}_{2}$ measurements

Time-resolved emission of ${ }^{1} \mathrm{O}_{2}$ at $1270 \mathrm{~nm}$ was studied in air saturated solutions of RC5 at room temperature. Photoexcitation of Chl (and presumably Phe) molecules at the $\mathrm{Q}_{\mathrm{y}}$ band (i.e., $675 \mathrm{~nm}$ ) was achieved by using an excitation pulse with a duration of about $7 \mathrm{~ns}$ and an energy of about $1 \mathrm{~mJ}$ delivered by an optical parameter oscillator pumped by a Nd:YAG laser operating at $10 \mathrm{~Hz}$ (B.M. Industries, Evry Cedex, France). The phosphorescence emission of ${ }^{1} \mathrm{O}_{2}$, collected at a right angle to the excitation beam, was focused on the photocathode of an infra-red-sensitive photomultiplier tube R550942 (Hamamatsu Photonics K.K., Hamamatsu, Japan). Further details about the experimental set-up, including the filters used for isolating the phosphorescence signal and digital acquisition of the photomultiplier output have already been described with sufficient detail in reference (31). The photogeneration of ${ }^{1} \mathrm{O}_{2}$ by RC5 was investigated in deuterium oxide $\left(\mathrm{D}_{2} \mathrm{O}\right)$, where small aliquots of highly-concentrated RC5 samples were dispersed. The content of water in $\mathrm{D}_{2} \mathrm{O}$ was always below $1 \%(\mathrm{v} / \mathrm{v})$. Additionally, solutions of MB with increasing concentrations of Trolox were used to photosensitize 


\begin{abstract}
${ }^{1} \mathrm{O}_{2}$ in the (aqueous) assay buffer and to determine the total bimolecular rate constant for the scavenging of ${ }^{1} \mathrm{O}_{2}$ by Trolox.
\end{abstract}

Electrophoresis and Western blot analysis

Aliquots of $10 \mu \mathrm{L}$ of RC5 with an absorbance (for a path length of $1 \mathrm{~cm}$ ) of 0.3 at $675 \mathrm{~nm}$ were subjected to $6 \mathrm{M}$ urea, $12 \%$ (w/v) SDS-polyacrylamide gel electrophoresis (SDS-PAGE) following the method of Laemmli (32) and transferred for $1.25 \mathrm{~h}$ to nitrocellulose membranes for Western blot analysis. The RC5 samples were incubated with the electrophoresis denaturing buffer overnight at room temperature containing 8 M urea before being subjected to SDS-PAGE. Antibodies against the luminal-exposed side of the C-terminal region of the D1 (AS05 084) and D2 (AS06 146) proteins were purchased from Agrisera (Agrisera AB, Vännäs, Sweden). The immunodetection of the D1 and D2 proteins was visualized with the DAB (3,3’-diaminobenzidine tetrahydrochloride) substrate kit (Pierce Biotechnology, Rockford, IL). Electrophoresis gels were stained with Coomassie R 250.

The analysis of the protein oxidation of RC5 followed the steps described in the OxyBlot $^{\mathrm{TM}}$ protein oxidation detection kit from Millipore (Millipore, Billerica, MA). After the sample treatment of RC5 in the oxygen electrode, the RC5 samples were concentrated using a swinging bucket rotor at $4000 \mathrm{~g}$ in Amicon ultra-15 centrifugal filter units with a cut-off of $100 \mathrm{kDa}$ (Millipore, Billerica, MA). A volume of $7.5 \mu \mathrm{L}$ of RC5 with an initial absorbance (for a path length of $1 \mathrm{~cm}$ ) of 10 at $675 \mathrm{~nm}$ was chemically modified with 2,4-dinitrophenylhydrazine (DNPH). The carbonylated proteins were identified using the anti-DNP antibody and visualized with DAB. 


\section{Results}

\section{Absorption and LD spectra of RC5}

The absorption spectrum of RC5 is shown in Figure 1a. The spectral features and pigment composition of RC5 have already been described in $(27,28)$ and will not be further commented on here. The absorption spectrum is presented in order to facilitate explanations of the LD features of RC5 found in the Car region and the photobleaching of the pigments during the exposure of RC5 to several light and chemical treatments. The LD spectrum of RC5 has been studied in the $\mathrm{Chl} \mathrm{Q}_{\mathrm{y}}$ region (33), but not in the Car region. RC5 is characterized by the presence of one $\beta$-Car molecule (27), and therefore, the LD spectrum can give us the opportunity of establishing which $\beta$-Car is lost during isolation of RC5: the "blue" $\beta$-Car in D1 (with peaks at 427,459 and $490 \mathrm{~nm}$ ) and oriented almost perpendicular to the plane of the membrane, or the "red" $\beta$-Car in D2 (with peaks at 442, 474 and $506 \mathrm{~nm}$ ) and lying close to the plane of the membrane (34-36). The removal of one of these two $\beta$-Car molecules inevitably leads to absorbance changes in the Car region, and an enhancement of the LD features of the remaining $\beta$-Car molecule. The inset in Figure 1 shows that, apart from some small wavelength intervals, $\Delta \mathrm{A}<0$ in the entire region of Car absorption and there are pronounced negative peaks at 458 and $485 \mathrm{~nm}$; these observations allow us to conclude that the residing $\beta$-Car molecule is oriented nearly perpendicular to the membrane plane (i.e., $\beta$-Car ${ }_{489}$ ). The absorption spectra of RC5 after light and chemical treatments depicted in Figure $1 \mathrm{~b}$ are discussed below.

Direct detection of ${ }^{1} \mathrm{O}_{2}$ emission in $\mathrm{RC} 5$ samples 
Phosphorescence emission of ${ }^{1} \mathrm{O}_{2}$ at $1270 \mathrm{~nm}$ endogenously produced by RC5 in $\mathrm{D}_{2} \mathrm{O}$ is depicted in Figure 2. The observed kinetic traces were well-fitted to the following bi-exponential function $I(t)=a\left(k_{1}-k_{2}\right)^{-1}\left[\exp \left(-k_{2} t\right)-\exp \left(-k_{1} t\right)\right]$, where $a>$ 0 , and the larger (smaller) of the two rate constants determines the rise (decay) of the emission signal; here we will identify the larger rate constant with $k_{1}$. In order to conclude unambiguously that the emission monitored at $1270 \mathrm{~nm}$ was due to the photogeneration of ${ }^{1} \mathrm{O}_{2}$ by $\mathrm{RC} 5$, the solution was deoxygenated by bubbling a stream of $\mathrm{N}_{2}$ through it for 15-20 min or a small amount of $\mathrm{NaN}_{3}$ was added. After such a treatment, emission from ${ }^{1} \mathrm{O}_{2}$ was no longer detectable (data not shown). The temporal profile of ${ }^{1} \mathrm{O}_{2}$ emission showed that $\tau_{1} \equiv 1 / k_{1}=13 \pm 1 \mu \mathrm{s}$, a value that accords with those reported for the photogeneration of ${ }^{1} \mathrm{O}_{2}$ by standard RC6 (37). In this latter work, the rise constant was observed to be concentration- and laser power-dependent (here not investigated) and shown to correspond with the lifetime of ${ }^{3} \mathrm{P}$ in air-saturated solutions. The decay time for ${ }^{1} \mathrm{O}_{2}$ determined in our study, $\tau_{2} \equiv 1 / k_{2}=54 \pm 2 \mu \mathrm{s}$, is smaller than the natural lifetime, approximately $70 \mu \mathrm{s}$, for ${ }^{1} \mathrm{O}_{2}$ in $\mathrm{D}_{2} \mathrm{O}$, presumably due to the presence of trace amounts of water and other additives present in the assay buffer.

Since the main aim of this study was to investigate the photoprotection of the D1 and D2 proteins, and the pigments within RC5 by Trolox, we first analyzed whether its presence in the medium affected the kinetic traces of ${ }^{1} \mathrm{O}_{2}$ photosensitized by RC5. Trolox was found to be a strong scavenger of ${ }^{1} \mathrm{O}_{2}$ and, in fact, submillimolar concentrations of Trolox already produced a visible effect on the temporal profile of ${ }^{1} \mathrm{O}_{2}$ emission. The result of adding $25 \mu \mathrm{M}$ Trolox to RC5 is illustrated in Figure 2 to serve as an example. Following the above bi-exponential fitting, the new values for the rise time and decay time were $12 \pm 1 \mu \mathrm{s}$ and $38 \pm 2 \mu \mathrm{s}$, respectively. The change in the kinetic 
Total and chemical bimolecular rate constants for the scavenging of ${ }^{1} \mathrm{O}_{2}$ by Trolox in the assay buffer

In brief, the ${ }^{1} \mathrm{O}_{2}$ deactivation by Trolox has been demonstrated to take place through the reversible formation of an exciplex with partial charge transfer character $(2$, 24,38 ); this exciplex may undergo intersystem crossing and dissociate (physical quenching), or it may yield an allylic hydroperoxide intermediate that forms to Trolox $\mathrm{Q}$ (chemical quenching). $\mathrm{MB}$ was used as the ${ }^{1} \mathrm{O}_{2}$ photosensitizer to determine both the physical and chemical quenching constants of ${ }^{1} \mathrm{O}_{2}$ by Trolox. The analysis was performed in the assay buffer, where later the photoinduced consumption of molecular oxygen in RC5 samples would be investigated (see discussion). The temporal profile of ${ }^{1} \mathrm{O}_{2}$ emission using increasing concentrations of Trolox is depicted in Figure 3a. Details of the build-up and subsequent decay of the concentration of ${ }^{1} \mathrm{O}_{2}$ in water when $\mathrm{MB}$ is used as the photosensitizer are given in reference (31). Still, it is worth noting that the 
bi-exponential fitting of the temporal profile of ${ }^{1} \mathrm{O}_{2}$ emission in the assay buffer in the absence of Trolox indicated a decay time of $4.6 \pm 0.2 \mu \mathrm{s}$ for ${ }^{1} \mathrm{O}_{2}$, which is larger than that determined in pure water $3.7 \pm 0.4 \mu \mathrm{s}(31)$, indicating that ${ }^{1} \mathrm{O}_{2}$ is partitioned between the aqueous phase and the detergent micelles, where the lifetime of ${ }^{1} \mathrm{O}_{2}$ is longer due to the more hydrophobic environment (25). The linear fitting of the corresponding decay rate constants is depicted in the inset of Figure 3a. A bimolecular rate constant $\left(k_{\mathrm{t}}\right)$ of $(2.4 \pm 0.2) \times 10^{8} \mathrm{M}^{-1} \mathrm{~s}^{-1}$ for the scavenging of ${ }^{1} \mathrm{O}_{2}$ by Trolox was derived from the analysis. This value represents the total rate constant under our experimental conditions and therefore further efforts to distinguish between physical and chemical quenching were undertaken. To determine the chemical quenching constant for Trolox, furfuryl alcohol was used as a reference. This compound is water soluble and its chemical rate constant $\left(k_{\mathrm{r}}\right)$ in this medium is known to be $1.2 \times 10^{8} \mathrm{M}^{-1} \mathrm{~s}^{-1}(38,39)$. The chemical quenching constant for Trolox was obtained by comparing the rates of oxygen consumption by both furfuryl alcohol and Trolox in a range of concentrations where these two compounds maintained a linear relationship with the oxygen consumption rate. While furfuryl alcohol showed linearity for a broad range of concentrations, the concentration of Trolox had to be kept below $0.2 \mathrm{mM}$ in the assay buffer to ensure a linear dependence. For the range of concentrations depicted in Figure 3b, a chemical quenching constant $\left(k_{\mathrm{r}}\right)$ of $(1.8 \pm 0.1) \times 10^{8} \mathrm{M}^{-1} \mathrm{~s}^{-1}$ for Trolox was obtained, giving a final ratio between the total rate constant and the chemical one of $\sim 1.3$. This result suggests that most of the ${ }^{1} \mathrm{O}_{2}$ photogenerated by MB chemically reacts with Trolox in the assay buffer.

Photoinduction of oxygen consumption in RC5 samples 
Based on the results presented above, it was expected that a substantial fraction of ${ }^{1} \mathrm{O}_{2}$ photosensitized by RC5 diffusing out from the $\mathrm{P}_{680}$ niche into the surrounding medium would suffer chemical quenching by Trolox. Before we describe these results, let us explain the effect of the $\mathrm{pH}$-dependent solubility of Trolox on the oxygen consumption when MB is used as the photosensitizer. Trolox dissolves poorly in water, but its solubility increases when its carboxylic group is dissociated. At the $\mathrm{pH}$ of the assay buffer (i.e., pH 7.2), the carboxylic group of Trolox is dissociated and Trolox becomes rather soluble. The rates of oxygen consumption is insensitive to the solvent (assay buffer or $50 \mathrm{mM}$ Tris- $\mathrm{HCl} \mathrm{pH}$ 7.2), showing that Trolox is free in solution and the presence of detergent micelles has little effect on its solubility (Figure 4a, traces 5 and 6). In contrast, unbuffered solutions containing Trolox show light scattering due to the poor solubility of the non-dissociated Trolox (data not shown); therefore, oxygen consumption measurements were not undertaken in these solutions. Light scattering did not occur if $0.01 \%(\mathrm{w} / \mathrm{v}) \mathrm{DM}$ was present in unbuffered solutions, indicating that the non-dissociated Trolox molecules were solubilized in the detergent micelles. When the MB-photoinduced oxygen consumption was measured in $0.01 \%$ (w/v) DM, the oxygen consumption rate decreased to about $20 \%$ of the value in the absence of DM (Figure 4a, trace 2). However, it was not possible (at this point) to distinguish whether the severe decrease in the rate of oxygen consumption was due to a change in the ratio between the total and chemical rate constants, or simply because the detergent molecules hindered the chemical reaction between ${ }^{1} \mathrm{O}_{2}$ and Trolox. Here, it is worth underlining that both MB and RC5 are photosensitizers of ${ }^{1} \mathrm{O}_{2}$, but they behave differently in the sense that MB produces ${ }^{1} \mathrm{O}_{2}$ in the aqueous medium (i.e., exogenous origin with regard to the detergent micelles), while RC5 produces it inside the micellar medium (i.e., endogenous origin). If the decrease in the rate of oxygen consumption by Trolox is ascribed to 
changes in the ratio between the total and chemical rate constants, one would expect that it should also apply to conditions in which ${ }^{1} \mathrm{O}_{2}$ is endogenously produced. If the rates of molecular oxygen consumption by Trolox are now compared (i.e., when RC5 is dispersed in the assay buffer or simply in $0.01 \%(w / v) ~ D M)$, the ratio between both rates indicates that $\sim 70 \%$ of the rate of oxygen consumption by Trolox still remains in $0.01 \%(w / v)$ DM (Figure 4a, traces 3 and 4), in opposition to the above observation with MB. This result indicates that Trolox is still an efficient chemical quencher of ${ }^{1} \mathrm{O}_{2}$, even when this compound becomes part of detergent micelles containing RC5. However, this experiment cannot yet exclude the possibility that the physical rate constant for the quenching of ${ }^{1} \mathrm{O}_{2}$ by Trolox increases in the detergent micelles (see discussion). For all the assayed concentrations of Trolox, we always found that the photoinduced oxygen consumption rate by Trolox was always higher when RC5 was dispersed in the assay buffer (Figure 4b), suggesting the concentration of Trolox was not a limiting factor. Briefly, RC5 samples in the absence of ${ }^{1} \mathrm{O}_{2}$ scavengers also hold a slight, but a clear, rate of oxygen consumption (Figure 4a, trace 1).

A comparative concentration-dependence analysis was performed with Trolox and other scavengers of ${ }^{1} \mathrm{O}_{2}$ in order to determine the maximum rate of oxygen consumption when RC5 was the photosensitizer (Figure 4b). An analysis of the oxygen consumption rates showed that $95 \%$ of the maximum rate for Trolox was achieved for a concentration of $1.7 \mathrm{mM}\left(\sim 60 \mu \mathrm{M}\right.$ of $\mathrm{O}_{2}$ per $\left.\mathrm{min}^{-1}\right)$ in the assay buffer and $1.6 \mathrm{mM}(\sim 40$ $\mu \mathrm{M}$ of $\mathrm{O}_{2}$ per $\mathrm{min}^{-1}$ ) in $0.01 \%$ (w/v) DM, whereas the concentrations of L-histidine and furfuryl alcohol required to reach $95 \%$ of the maximum rates were greater, i.e., $4 \mathrm{mM}$ $\left(\sim 70 \mu \mathrm{M}\right.$ of $\mathrm{O}_{2}$ per $\left.\min ^{-1}\right)$ and $7 \mathrm{mM}\left(\sim 120 \mu \mathrm{M}\right.$ of $\mathrm{O}_{2}$ per $\left.\min ^{-1}\right)$, respectively (both values estimated by extrapolation of the fitted monoexponential curves). It is clear that the maximum rate of oxygen consumption for Trolox is lower than that for L-histidine 
and furfuryl alcohol at high concentrations (i.e., beyond $2.5 \mathrm{mM}$ ), which suggests that the diminution in the rate of oxygen consumption is due to the poor solubility of Trolox; however, when the concentration of Trolox is kept below its solubility limit (i.e., around $1 \mathrm{mM}$ or below), this scavenger has the largest rate of oxygen consumption as compared to L-histidine and furfuryl alcohol. This result is similar to the previous one where MB was used as the photosensitizer of ${ }^{1} \mathrm{O}_{2}$ to determine the chemical quenching of Trolox (Figure 3b).

To verify that the photoinduced consumption of oxygen was due to the photogeneration of ${ }^{1} \mathrm{O}_{2}$ by $\mathrm{RC} 5$ and not to the generation of other reactive oxygen species (ROS), several control experiments were performed. The replacement of water by $\mathrm{D}_{2} \mathrm{O}$ in the medium increases the rate of oxygen consumption by about $60 \%$ when using $2.5 \mathrm{mM}$ L-Histidine. No significant changes in the photoinduced rate of oxygen consumption were observed when 500 units (or more) per mL of superoxide dismutase or catalase were present in the assay buffer, indicating that the formation of other ROS such as $\mathrm{H}_{2} \mathrm{O}_{2}$ or $\mathrm{O}_{2}{ }^{-{ }^{-}}$had a very minor role (if any) under our experimental conditions (data not shown).

\section{Pigment photobleaching of RC5}

So far we have shown that Trolox can be an efficient scavenger of ${ }^{1} \mathrm{O}_{2}$ endogenously produced by RC5, but we have not yet established if this compound can play any photoprotective role in RC5 samples and prevent the photobleaching of pigments and photodamage of the D1 and D2 proteins inside the PSII RC complex. Histidine and $\mathrm{NaN}_{3}$ are not able to photoprotect pigments in RC6 (40) and we have found that this is true also for the pigments in RC5 (data not shown). To investigate the 
photoprotective role of Trolox, a concentration of $1 \mathrm{mM}$ Trolox was chosen because the rate of oxygen consumption in the assay buffer was higher than that for $1 \mathrm{mM} \mathrm{L}_{\mathrm{L}}$ histidine or $1 \mathrm{mM}$ furfuryl alcohol (Figure $4 \mathrm{~b}$ ). While high light treatment under anaerobiosis showed subtle changes in the absorption spectrum of RC5 and presumably a slight increase in the light scattering of the solution (Figure 1a), the illumination under aerobiosis brought an irreversible and substantial photobleaching of pigments in RC5 after 2 min of high light treatment. These two experimental conditions were compared with high light treatments of RC5 in the presence of $1 \mathrm{mM}$ Trolox in the assay buffer as well as in $0.01 \%$ (w/v) DM. Clearly, Trolox cannot protect the pigments of RC5 from irreversible photobleaching, and the level of damage is similar to that seen under aerobiosis in the absence of ${ }^{1} \mathrm{O}_{2}$ quenchers. The peak position of the photobleached pigments at $678 \mathrm{~nm}$ in the $\mathrm{Q}_{\mathrm{y}}$ region and $485 \mathrm{~nm}$ in the blue region are ascribed to the loss of $\mathrm{P}_{680}$ and the $\beta$-Car molecule (41). No significant differences could be established between the two treatments with Trolox, even when there is a clear difference in the rate of oxygen consumption by Trolox in the assay buffer and in $0.01 \%(\mathrm{w} / \mathrm{v}) \mathrm{DM}$ (Figure $4 b)$.

Western blot analyses

After the high light treatment for $2 \mathrm{~min}$, all the RC5 samples were subjected to Western blot analysis to determine whether any of the above quenchers of ${ }^{1} \mathrm{O}_{2}$ could avoid the photodamage of the D1 protein. Control RC5 reveals the presence of two bands that react against the D1 antibody (Figure 5a, lane 1). The lower band corresponds with the monomeric D1 protein ( 32 kDa); the upper, with the heterodimer D1/D2 ( 66 kDa), which in fact was found as the most prominent band (Figure $5 \mathrm{~b})$, an 
observation that accords with the study by Barber and co-workers (42). A third, weak band with a molecular mass of $\sim 41 \mathrm{kDa}$ (Figure $5 \mathrm{~b}$ ) was often observed to react against the D1 antibody. This third band corresponds with an adduct between the D1 protein and the $\alpha$ subunit of cytochrome $b_{559}$. A second Western blot analysis confirmed that the antibody against the $\alpha$-subunit of cytochrome $b_{559}$ reacted with the band of $\sim 41 \mathrm{kDa}$ (data not shown). This band was present in the SDS-PAGE profile of RC5 (27) and it suggests that the RC5 isolation procedure gives rise to a preparation that contains some adduct and breakdown products not present in standard RC6. Adducts between the D1 protein and the $\alpha$ subunit of cytochrome $b_{559}$ have been described under several oxidative and photoinhibitory conditions (43). Control experiments under aerobic and anaerobic conditions clearly showed that the photodamage of the D1 protein is oxygen dependent (Figure 5a, lanes 2 and 3), and that an efficient physical quencher of ${ }^{1} \mathrm{O}_{2}$ such as $\mathrm{NaN}_{3}$ at a concentration of $2.5 \mathrm{mM}$ was not able to prevent the $\mathrm{D} 1$ protein from photodamage (Figure 5a, lane 8). When the potential photoprotective role of the three scavengers, when dissolved in the assay buffer, was compared, photodamage of the D1 protein was evident (Figure 5a, lanes 4, 6 and 7). Among the several conditions assayed, only the treatment with Trolox in $0.01 \%(\mathrm{w} / \mathrm{v}) \mathrm{DM}$ was able to prevent significantly the photodamage of D1 (Figure 5a, lane 5). This intriguing result suggests that Trolox in the detergent micelles can get close enough to the D1 protein, but not to the pigments.

When the ${ }^{1} \mathrm{O}_{2}$-mediated photodamage of the D2 was investigated under the same experimental conditions, the results were very similar to those described for the D1 protein (Figure 5c). A drastic depletion of the monomeric D2 band was observed, together with a slight shift of the band toward the cathodic end of the gel, under aerobic conditions (Figure 5c, lane 2). The shift was more evident in the band of the heterodimer D1/D2, which became broader (Figure 5c, lane 2). The depletion of the 
monomeric D2 band and the broadening of the heterodimer D1/D2 band were also present in the other experimental conditions in which the ${ }^{1} \mathrm{O}_{2}$ scavenger was dissolved in the assay buffer (Figure 5c, lanes 4, 6-8). Only when Trolox was in $0.01 \%$ (w/v) DM, the photodamage of the D2 was less pronounced (Figure 5c, lanes 5). Although the broadening of the heterodimer D1/D2 band was small, the monomeric D2 band became weaker than under anaerobic conditions and it suggests that the D2 protein is slightly more prone to photodamage than the $\mathrm{D} 1$ protein in RC5.

It is worth noting that no fragmented products of the D1 and D2 proteins were visualized in the Western blot analyses, supporting the view that the proteolytic cleavage of the D1 protein requires the presence of members of the Deg and FtsH protease families (44).

To determine the level of protein oxidation in RC5 after the treatments, the samples were derivatized with DNPH and the carbonyl modified amino acids of the protein matrix of RC5 were identified using the anti-DNP antibody. When the carbonylation levels of control RC5 under aerobic and anaerobic conditions were compared, a significant difference in the protein oxidation was found between both samples (Figure 6, lanes 1 and 2). Under aerobic conditions (and the other conditions), some protein aggregation was observed at the top of lane after derivatization with DNPH that could be responsible for the continuous background of the unresolved proteins of RC5. Despite the band smearing, two faint bands were observed at approximately 30 and $50 \mathrm{kDa}$, corresponding with the monomeric D1 and D2 proteins, and the heterodimer D1/D2, respectively; these bands and the absence of fragmented products suggest that ${ }^{1} \mathrm{O}_{2}$ causes only oxidative damage on the two proteins, but does not trigger their chemical cleavage. 
As expected, Trolox in the assay buffer cannot photoprotect RC5 (Figure 6, lane 3). Intriguingly, Trolox in $0.01 \%$ (w/v) DM can only photoprotect to some extent, but not at the level observed under anaerobic conditions, if the intensities of oxidized proteins in their respective lanes are compared (Figure 6, lane 2 and 4). The addition of $\mathrm{NaN}_{3}$ to the assay buffer confirms the view that this compound quenches ${ }^{1} \mathrm{O}_{2}$ in the aqueous surrounding medium, but it cannot photoprotect RC5. In this latter case the level of protein oxidation of RC5 is similar to the one reached under aerobic conditions (Figure 6, lane 5). If the Western blot analyses carried out with the D1 and D2 antibodies are compared with the OxyBlot analysis, one can concluded that Trolox in $0.01 \%(w / v)$ DM cannot provide equal photoprotection to all the regions of the D1 and D2 proteins.

\section{Discussion}

The role of Trolox in the in vitro photoprotection of pigments and the D1 and D2 proteins of PSII RC has been investigated with the aim of shedding more light on the role of vitamin $\mathrm{E}$ as a scavenger of ${ }^{1} \mathrm{O}_{2}$ in thylakoids and on how this prenyllipid prevents the photodamage of the D1 protein in vivo $(13,14,45,46)$. Our main conclusion is that, under certain experimental conditions, Trolox can indeed partly protect the D1 protein from photodamage. However, our view of as to how such protection takes place calls into question the physiological role of vitamin $\mathrm{E}$ in the photoprotection of the D1 protein when it is assembled into PSII. Before we discuss this issue, let us examine the results obtained by the analyses of the LD spectrum and the temporal profile of the phosphorescence emission of ${ }^{1} \mathrm{O}_{2}$, when RC5 or MB has been used as the ${ }^{1} \mathrm{O}_{2}$ photosensitizer. 
RC5 is characterized by the loss of one $\beta$-Car molecule during isolation. Since 1995, when the procedure of the RC5 purification was first published (27), the location of the bound $\beta$-Car molecule has remained elusive. Attempts to determine its location inside RC5 were undertaken in two independent spectroscopic studies $(28,47)$. In both of them, it was proposed that the bound $\beta$-Car in RC5 was in the D1 protein. This conclusion has now been reinforced by the LD results reported here. The more negative $\mathrm{LD}$ features in the Car region confirm that the $\beta$-Car molecule remaining in RC5 is oriented perpendicular to the membrane plane. Nevertheless, some spectral features of $\beta$-Car ${ }_{507}$ can still be observed, but these can be ascribed to trace amounts of this Car molecule in RC5 on the basis of our pigment analysis by HPLC and the spectral reconstruction method (28).

RC6 can be purified with one or two $\beta$-Car molecules and it has been demonstrated that the intensity of the temporal profile of ${ }^{1} \mathrm{O}_{2}$ emission by these two types of RC6 depends on the number of $\beta$-Car molecules within the complex (48). Telfer and co-workers observed that the yield of ${ }^{1} \mathrm{O}_{2}$ diffusing into the surrounding medium, from which the phosphorescence is emitted, was higher in RC6 with one $\beta$-Car molecule because the concentration of ${ }^{1} \mathrm{O}_{2}$ quenchers inside the protein matrix was lower. Since the detected phosphorescence emission originates only from the ${ }^{1} \mathrm{O}_{2}$ that diffuses into the medium (3), no differences in the deactivation rate constants were observed between both types of RC6. Admittedly, we cannot perform similar comparison in RC5 preparations, but the absence of one $\beta$-Car molecule in RC5 is seen as an advantage, for it leads to a larger intensity of the ${ }^{1} \mathrm{O}_{2}$ emission, without affecting the values for the rise and decay kinetic constants, since these parameters were found to be very similar to those reported for RC6 $(37,48)$. This implies that the conclusions drawn from this study are equally applicable to standard PSII RC. 
The ratio between the total and chemical bimolecular rate constants for the scavenging of ${ }^{1} \mathrm{O}_{2}$ by Trolox was calculated in the assay buffer using MB, instead of RC5, as the ${ }^{1} \mathrm{O}_{2}$ photosensitizer. One straightforward explanation for this choice is that the total deactivation rate constant of ${ }^{1} \mathrm{O}_{2}$ depends on the surrounding medium (i.e., type of solvent and presence of ${ }^{1} \mathrm{O}_{2}$ quenchers), but has no dependence on the source of ${ }^{1} \mathrm{O}_{2}$. A second explanation is that the ratio between the total and chemical bimolecular rate constants for the scavenging of ${ }^{1} \mathrm{O}_{2}$ had to be calculated in an aqueous buffer, where the lifetime of ${ }^{1} \mathrm{O}_{2}$ in the surrounding medium was limited to a few $\mu \mathrm{s}$, instead of tens of $\mu \mathrm{s}$ as in $\mathrm{D}_{2} \mathrm{O}$. This ensured that the level of pigment and D1 photodamage was simply a direct consequence of the ${ }^{1} \mathrm{O}_{2}$ scavenged inside the protein matrix, not the result of other factors such as the return of ${ }^{1} \mathrm{O}_{2}$, after it has diffused into the surrounding medium where it has a longer lifetime (49), to the PSII RC protein matrix. Under our experimental conditions, we determined a ratio of $\sim 1.3$ between the total and chemical bimolecular rate constants for the scavenging of ${ }^{1} \mathrm{O}_{2}$ (i.e., $k_{\mathrm{t}}=(2.4 \pm 0.2) \times 10^{8} \mathrm{M}^{-1} \mathrm{~s}^{-1}$ and $k_{\mathrm{r}}=(1.8 \pm 0.1) \times 10^{8} \mathrm{M}^{-1} \mathrm{~s}^{-1}$, respectively), which clearly indicates that Trolox is a strong scavenger of ${ }^{1} \mathrm{O}_{2}$ and confirms that the chemical quenching for Trolox is more prominent than the physical one in polar environments (38). In surveying other reported values for the total and chemical bimolecular rate constants for the scavenging of ${ }^{1} \mathrm{O}_{2}$ by Trolox, we found values ranging from $1.3 \times 10^{7} \mathrm{M}^{-1} \mathrm{~s}^{-1}$ to $4.4 \times 10^{8} \mathrm{M}^{-1} \mathrm{~s}^{-1}$ in aqueous mixtures containing either $\mathrm{H}_{2} \mathrm{O}$ or $\mathrm{D}_{2} \mathrm{O}$ and other additives $(24,25,38,50,51)$. Our results are consistent with some of the values reported in Table 1. The variability of these values arises from the use of different mixtures with organic solvents or the presence of detergent micelles in the medium. It is also worthwhile to note that the decay time of ${ }^{1} \mathrm{O}_{2}$ in the assay buffer (containing $0.01 \%$ (w/v) "non-ionic" DM), namely 4.6 $\pm 0.2 \mu \mathrm{s}$, is slightly larger than that in water $(\sim 3.7 \mu \mathrm{s})(31)$ and close to that reported 
in anionic or cationic detergent solutions $(\sim 4.5 \mu \mathrm{s})(25)$. This observation has been explained on the basis of the partitioning of ${ }^{1} \mathrm{O}_{2}$ between the bulk water phase and the interfacial region around the detergent micelles and the longer decay time of ${ }^{1} \mathrm{O}_{2}$ in the hydrophobic environment (25).

The difference in the photoinduced oxygen consumption by Trolox when this ${ }^{1} \mathrm{O}_{2}$ quencher is dispersed in the aqueous medium (assay buffer) or is bound to the detergent micelles in an unbufferred solution $(0.01 \%(\mathrm{w} / \mathrm{v}) \mathrm{DM})$ shows that the activity of Trolox as a chemical quencher of ${ }^{1} \mathrm{O}_{2}$ falls by about $30 \%$ in the latter solution. This loss of activity is similar for all the assayed concentrations of Trolox and it indicates that the concentration of Trolox in the medium is not the limiting factor. Several arguments can be used to explain this observation. One is that Trolox, when bound to the detergent micelles in unbuffered solutions, finds itself in a less polar environment, so that the ratio between the total and chemical bimolecular rate constants for the scavenging of ${ }^{1} \mathrm{O}_{2}$ increases as observed in other organic solvent mixtures (38). Another explanation is that Trolox is in its non-dissociated form in the detergent micelles. Based on the $\mathrm{p} K$ value of the carboxylic group (i.e., 3.89), a dissociation coefficient $(\alpha)$ of $\sim 0.3$ at $[\text { Trolox }]_{\mathrm{T}}=1 \mathrm{mM}$ can be determined. The non-dissociated form of Trolox, $(1-$ $\alpha \sim 0.7$ ), is a better scavenger of ${ }^{1} \mathrm{O}_{2}$ than the mono-dissociated form (25), but has a smaller chemical rate constant (38), giving again as a result a higher ratio between the total and chemical bimolecular rate constants for the scavenging of ${ }^{1} \mathrm{O}_{2}$. A third explanation would be that Trolox quenches ${ }^{3} \mathrm{P}$, decreasing the ${ }^{1} \mathrm{O}_{2}$ yield of RC5 and consequently the oxygen consumption by Trolox. However, no evidence was found to support this last view based on our transient absorption spectroscopy analysis. Quenching of the triplet state of ${ }^{1} \mathrm{O}_{2}$ photosensitizers such as riboflavin by Trolox has been described in methanolic and aqueous solutions $(50,52)$, where both 
photosensitizer and quencher can freely diffuse. The fact that Trolox does not quench ${ }^{3} \mathrm{P}$ has important implications in our study. It implies that Trolox cannot reach the $\mathrm{P}_{680}$ niche and, consequently, cannot prevent the photogeneration of ${ }^{1} \mathrm{O}_{2}$ by inhibiting the triplet-triplet energy transfer from ${ }^{3} \mathrm{P}$ to ground state molecular oxygen. This also explains why the photobleaching of pigments in RC5 reaches equal levels under aerobic conditions with or without Trolox, and irrespective of whether the aqueous medium is the assay buffer or the $0.01 \%(\mathrm{w} / \mathrm{v}) \mathrm{DM}$ solution. It also follows that Trolox is unable to reach the membrane region of the protein matrix of $\mathrm{RC} 5$, leaving this region as well vulnerable to photodamage (see below).

As stated above, Trolox cannot photoprotect $\mathrm{P}_{680}$ from photobleaching in any situation studied here, but intriguingly it can partly photoprotect the D1 and D2 proteins under certain conditions. Here, it is worth noting that the Agrisera D1 and D2 antibodies, used in this study, only recognize the luminal-exposed side of the C-terminal region of the $\mathrm{D} 1$ and $\mathrm{D} 2$ proteins and that ${ }^{1} \mathrm{O}_{2}$ could cause oxidative damage in other regions of these two proteins (i.e., membrane regions) not recognized by these antibodies. The mono-dissociated Trolox, when dispersed in the assay buffer, shows a high rate of oxygen consumption, but this form is unable, as are L-histidine and furfuryl alcohol, to photoprotect the D1 protein. In contrast to this, the undissociated Trolox bound to the detergent micelles shows a lower rate of oxygen consumption (presumably because the ratio between the total and chemical bimolecular rate constants for the scavenging of ${ }^{1} \mathrm{O}_{2}$ is higher in the detergent micelles as discussed above), but it can photoprotect the luminal-exposed regions of the D1 and D2 proteins. One expects that Trolox can be equally close to the luminal- and stromal sides of the heterodimer D1/D2, where it quenches ${ }^{1} \mathrm{O}_{2}$ diffusing into the surrounding medium while protecting the D1 and D2 proteins. On the contrary, the accessibility of Trolox to the $\mathrm{P}_{680}$ niche within the 
protein matrix is expected to be hampered by the large A-B and C-D loops of the heterodimer D1/D2 as we can infer from our transient absorption analysis. The accessibility to the $\mathrm{P}_{680}$ niche would be even more difficult in intact PSII complexes where the extrinsic proteins and the bulky loops of the inner antennas CP47 and CP43 form a greater physical barrier (PDB 2AXT) (10). Havaux and co-workers (15) suggested that a fraction of the tocopherol pool is located very close to PSII for efficient quenching of ${ }^{1} \mathrm{O}_{2}$ at its site of production. If there are such tocopherol molecules, their chromanol ring will have to be close to the $\mathrm{P}_{680}$ niche. However, on the basis of our own results with Trolox and the known dynamics of tocopherol molecules in membranes $(21,22)$, it is difficult to envisage a physiological situation where tocopherol molecules can reach the $\mathrm{P}_{680}$ niche, but Trolox, with a higher mobility and larger scavenging activity $(21,22)$, cannot. This is further supported by other experiments where the kinetics and dynamics of ${ }^{1} \mathrm{O}_{2}$ scavenging by $\alpha$-tocopherol were investigated with photosensitizers inside and outside membrane models (53). In the former study, the total and chemical bimolecular rate constants for the scavenging of ${ }^{1} \mathrm{O}_{2}$ by $\alpha$-tocopherol was demonstrated to be high when ${ }^{1} \mathrm{O}_{2}$ was produced on the membrane surface, but low within the hydrophobic region of the membrane, where the concentration of the $\mathrm{OH}$ groups of $\alpha$-tocopherol was smaller. Similar conclusions were reached when the antioxidant activities of vitamin $\mathrm{E}$ and Trolox were compared in lipid model membranes and both lipophilic and hydrophilic azocompounds were used to generate peroxyl radicals (54). Based on these arguments, it seems plausible that tocopherol molecules with the $\mathrm{OH}$-group exposed to the surface of the thylakoid membrane will behave like Trolox, providing better photoprotection to the surface-exposed regions of the D1 and D2 proteins than to the source of ${ }^{1} \mathrm{O}_{2}$ (i.e., $\mathrm{P}_{680}$ ) or the membrane region of these two proteins. A similar proposal has already been advanced by Pospísil (2011) (18), who 
suggested that $\alpha$-tocopherol with the chromanol ring close to the membrane edge scavenges those ${ }^{1} \mathrm{O}_{2}$ molecules that escape from the antioxidant barrier formed by carotenoids within the thylakoid membrane.

Recently, the photoprotection of the D1 protein by $\alpha$-tocopherol has been questioned in cyanobacteria and higher plants. It has been demonstrated that the absence of $\alpha$-tocopherol in the mutants slr0090 of Synechocystis sp. PCC 6803 and vtel of Arabidopsis thaliana suppresses the biosynthesis of the D1 protein during photoinhibition, but does not exacerbate the photodegradation of the D1 protein (19, 20 ). These latter studies cast doubt on the role of $\alpha$-tocopherol in photoprotecting the D1 protein when it is assembled into PSII.

In conclusion, our results have demonstrated that Trolox is an efficient quencher of ${ }^{1} \mathrm{O}_{2}$ photosensitized by PSII RC and exhibits a particularly high chemical reactivity with ${ }^{1} \mathrm{O}_{2}$ in a polar medium. Trolox can photoprotect the surface-exposed regions of PSII RC in vitro; however, Trolox cannot prevent the photodamage of the Chl molecules of $\mathrm{P}_{680}$ and the membrane region of the heterodimer D1/D2, implying that Trolox quenches ${ }^{1} \mathrm{O}_{2}$ only when the latter reaches the outer surface of the protein matrix of PSII RC exposed to the polar medium. By extending this conclusion to other studies carried out with $\alpha$-tocopherol, we propose that, so far as PSII in vivo is concerned, $\alpha$ tocopherol might photoprotect the surface exposed regions of the D1 and D2 proteins, but the protection of $\mathrm{P}_{680}$ seems highly unlikely.

\section{Acknowledgement}

We thank Ms. Esther Ruth, Mr. Jaime Curto and Mr. José J. Martín for their technical assistance. 


\section{References}

1. Schweitzer, C., and Schmidt, R. (2003) Physical mechanisms of generation and deactivation of singlet oxygen, Chem. Rev. 103, 1685-1757.

2. Gorman, A. A. (1992) The bimolecular reactivity of singlet molecular oxygen, in Advances in photochemistry (Volman, D.H., Hammond, G.S., and Neckers D.C., Eds.), vol. 17, pp. 217-274, John Wiley and Sons, New York.

3. Gorman, A. A., and Rodgers, M. A. J. (1992) Current perspectives of singlet oxygen detection in biological environments, J. Photochem. Photobiol. B 14, $159-176$.

4. Foote, C. S. (1968) Mechanisms of photosensitized oxidation, Science 162, 963969.

5. Vass, I., Styring, S., Hundal, T., Koivuniemi, A., Aro, E. M., and Andersson, B. (1992) Reversible and irreversible intermediates during photoinhibition of photosystem II: Stable reduced $\mathrm{Q}_{\mathrm{A}}$ species promote chlorophyll triplet formation, Proc. Natl. Acad. Sci. U.S.A. 89, 1408-1412.

6. Takahashi, Y., Hansson, Ö., Mathis, P., and Satoh, K. (1987) Primary radical pair in the photosystem II reaction center, Biochim. Biophys. Acta 893, 49-59.

7. Durrant, J. R., Giorgi, L. B., Barber, J., Klug, D. R., and Porter, G. (1990) Characterisation of triplet states in isolated photosystem II reaction centres: oxygen quenching as a mechanism for photodamage, Biochim. Biophys. Acta $1017,167-175$. 
8. Santabarbara, S., Bordignon, E., Jennings, R. C., and Carbonera, D. (2002)

Chlorophyll triplet states associated with photosystem II of thylakoids, Biochemistry 41, 8184-8194.

9. Macpherson, A. N., Telfer, A., Barber, J., and Truscott, T. G. (1993) Direct detection of singlet oxygen from isolated photosystem II reaction centres, Biochim. Biophys. Acta 1143, 301-309.

10. Loll, B., Kern, J., Saenger, W., Zouni, A., and Biesiadka, J. (2005) Towards complete cofactor arrangement in the $3.0 \AA$ A resolution structure of photosystem II, Nature 438, 1040-1044.

11. Noguchi, T. (2002) Dual role of triplet localization on the accessory chlorophyll in the photosystem II reaction center: Photoprotection and photodamage of the D1 protein, Plant Cell Physiol. 43, 1112-1116.

12. Telfer, A. (2002) What is $\beta$-carotene doing in the photosystem II reaction centre?, Philos. Trans. R. Soc. Lond. B Biol. Sci. 357, 1431-1439.

13. Trebst, A., Depka, B., and Holländer-Czytko, H. (2002) A specific role for tocopherol and of chemical singlet oxygen quenchers in the maintenance of photosystem II structure and function in Chlamydomonas reinhardtii, FEBS Lett. $516,156-160$.

14. Krieger-Liszkay, and A. Trebst, A. (2006) Tocopherol is the scavenger of singlet oxygen produced by the triplet states of chlorophyll in the PSII reaction centre, $J$. Exp. Bot. 57, 1677-1684.

15. Havaux, M., Eymery, F., Porfirova, S., Rey, P., and Dormann, P. (2005) Vitamin E protects against photoinhibition and photooxidative stress in Arabidopsis thaliana, Plant Cell 17, 3451-3469. 
16. Kruk, J., and Trebst, A. (2008) Plastoquinol as a singlet oxygen scavenger in photosystem II, Biochim. Biophys. Acta 1777, 154-162.

17. Yadav, D. K., Kruk, J., Sinha, R. K., and Pospísil, P. (2010) Singlet oxygen scavenging activity of plastoquinol in photosystem II of higher plants: Electron paramagnetic resonance spin-trapping study, Biochim. Biophys. Acta 1797, 18071811.

18. Pospísil, P. (2011) Molecular mechanisms of production and scavenging of reactive oxygen species by photosystem II. Biochim. Biophys. Acta doi:10.1016/j.bbabio.2011.05.017.

19. Hakala-Yatkin, M., Sarvikas, P., Paturi, P., Mäntysaari, M., Mattila, H., Tyystjärvi, T., Nedbal, L., and Tyystjärvi, E. (2011) Magnetic field protects plants against high light by slowing down production of singlet oxygen. Physiol. Plant. 142, 26-34.

20. Inoue, S., Ejima, K., Iwai, E., Hayashi, H., Appel, J., Tyystjärvi, E., Murata, N., and Nishiyama, Y. (2011) Protection by $\alpha$-tocopherol of the repair of photosystem II during photoinhibition in Synechocystis sp PCC 6803, Biochim. Biophys. Acta $1807,236-241$.

21. Niki, E., and Noguchi, N. (2004) Dynamics of antioxidant action of vitamin E, Acc. Chem. Res. 37, 45-51.

22. Kagan, V. E., Serbinova, E. A., Bakalova, R. A., Stoytchev, T. S., Erin, A. N., Prilipko, L.L., and Evstigneeva, R.P. (1990) Mechanisms of stabilization of biomembranes by alpha-tocopherol. The role of the hydrocarbon chain in the inhibition of lipid peroxidation, Biochem. Pharmacol. 40, 2403-2413. 
23. Barclay, L. R. C., and Vinqvist, M. R. (1994) Membrane peroxidation: Inhibiting effects of water-soluble antioxidants on phospholipids of different charge types, Free Radic. Biol. Med. 16, 779-788.

24. Bisby, R. H., Morgan, C. G., Hamblett, I., and Gorman, A. A. (1999) Quenching of singlet oxygen by Trolox C, ascorbate, and amino acids: Effects of $\mathrm{pH}$ and temperature, J. Phys. Chem. A 103, 7454-7459.

25. Ohara, K., Kikuchi, K., Origuchi, T., and Nagaoka, S. (2009) Singlet oxygen quenching by trolox $\mathrm{C}$ in aqueous micelle solutions, J. Photochem. Photobiol. B 97, 132-137.

26. Mukai, K., Daifuku, K., Okabe, K., Tanigaki, T., and Inoue, K. (1991) Structureactivity relationship in the quenching reaction of singlet oxygen by tocopherol (vitamin E) derivatives and related phenols. Finding of linear correlation between the rates of quenching of singlet oxygen and scavenging of peroxyl and phenoxyl radicals in solution, J. Org. Chem. 56, 4188-4192.

27. Vacha, F., Joseph, D. M., Durrant, J. R., Telfer, A., Klug, D. R., Porter, G., and Barber, J. (1995) Photochemistry and spectroscopy of a five-chlorophyll reaction center of photosystem II isolated by using a Cu affinity column, Proc. Natl. Acad. Sci. U.S.A. 92, 2929-2933.

28. Arellano, J. B., González-Pérez, S., Vacha, F., Melø, T. B., and Naqvi, K. R. (2007) Reaction center of photosystem II with no peripheral pigments in D2 allows secondary electron transfer in D1, Biochemistry 46, 15027-15032.

29. Chapman, D. J., Gounaris, K., and Barber, J. (1988) Electron-transport properties of the isolated D1-D2-cytochrome $b-559$ photosystem II reaction centre, Biochim. Biophys. Acta 933, 423-431. 
30. Haworth, P., Tapie, P., Arntzen, C.J., and Breton, J. (1982) Orientation of pigments in the thylakoid membrane and in the isolated chlorophyll-protein complexes of higher-plants .2. linear dichroism spectra of isolated pigmentprotein complexes oriented in polyacrylamide gels at $300 \mathrm{~K}$ and $100 \mathrm{~K}$, Biochim. Biophys. Acta 682, 152-159.

31. Arellano, J. B., Yousef, Y. A., Melø, T. B., Mohamad, S. B. B., Cogdell, R. J., and Naqvi, K. R. (2007) Formation and geminate quenching of singlet oxygen in purple bacterial reaction center, J. Photochem. Photobiol. B 87, 105-112.

32. Laemmli, U. K. (1970) Cleavage of structural proteins during assembly of head of bacteriophage T4, Nature 227, 680-685.

33. Vacha, F. (1996) Isolation and characterisation of a new 5-chlorophyll a reaction centre of photosystem II, Faculty of Biological Sciences, PhD Thesis, University of South Bohemia, Ceske Budejovice.

34. Tomo, T., Mimuro, M., Iwaki, M., Kobayashi, M., Itoh, S., and Satoh, K. (1997) Topology of pigments in the isolated Photosystem II reaction center studied by selective extraction, Biochim. Biophys. Acta 1321, 21-30.

35. van Dorssen, R. J., Breton, J., Plijter, J. J., Satoh, K., van Gorkom, H. J., and Amesz, J. (1987) Spectroscopic properties of the reaction center and of the 47 kDa chlorophyll protein of photosystem II, Biochim. Biophys. Acta 893, 267-274.

36. Kwa, S. L. S., Newell, W. R., van Grondelle, R., and Dekker, J. P. (1992) The reaction center of photosystem II studied with polarized fluorescence spectroscopy, Biochim. Biophys. Acta 1099, 193-202.

37. Telfer, A., Oldham, T. C., Phillips, D., and Barber, J. (1999) Singlet oxygen formation detected by near-infrared emission from isolated photosystem II reaction centres: direct correlation between P680 triplet decay and luminescence 
rise kinetics and its consequences for photoinhibition, J. Photochem. Photobiol. B 48, 89-96.

38. Nonell, S., Moncayo, L., Trull, F., Amatguerri, F., Lissi, E. A., Soltermann, A. T., Criado, S., and Garcia, N. A. (1995) Solvent influence on the kinetics of the photodynamic degradation of trolox, a water-soluble model compound for vitamin E, J. Photochem. Photobiol. B 29, 157-162.

39. Scully, F. E., and Hoigne, J. (1987) Rate constants for reactions of singlet oxygen with phenols and other compounds in water, Chemosphere 16, 681-694.

40. Telfer, A., Bishop, S. M., Phillips, D., and Barber, J. (1994) Isolated photosynthetic reaction center of photosystem II as a sensitizer for the formation of singlet oxygen. Detection and quantum yield determination using a chemical trapping technique, J. Biol. Chem. 269, 13244-13253.

41. Telfer, A., De Las Rivas, J., and Barber, J. (1991) $\beta$-Carotene within the isolated photosystem II reaction center: photooxidation and irreversible bleaching of this chromophore by oxidized P680, Biochim. Biophys. Acta 1060, 106-114.

42. Barber, J., Chapman, D. J., and Telfer, A. (1987) Characterisation of a PS II reaction centre isolated from the chloroplasts of Pisum sativum, FEBS Lett. 220, $67-73$.

43. Lupinkova, L., and Komenda, J. (2004) Oxidative modifications of the photosystem II D1 protein by reactive oxygen species: From isolated protein to cyanobacterial cells, Photochem. Photobiol. 79, 152-162.

44. Nixon, J. P., Michoux, F., Yu, J., Boehm, M., and Komenda, J. (2010) Recent advances in understanding the assembly and repair of photosystem II, Ann. Bot. $106,1-16$. 
45. Kruk, J., Holländer-Czytko, H., Oettmeier, W., and Trebst, A. (2005) Tocopherol as singlet oxygen scavenger in photosystem II, J. Plant Physiol. 162, 749-757.

46. Krieger-Liszkay, A., Fufezan, C., and Trebst, A. (2008) Singlet oxygen production in photosystem II and related protection mechanism, Photosynth. Res. $98,551-564$.

47. Losi, A., Yruela, I., Reus, M., Holzwarth, A. R., and Braslavsky, S. E. (2003) Structural changes upon excitation of D1-D2-Cyt $b_{559}$ photosystem II reaction centers depend on the $\beta$-carotene content, Photochem. Photobiol. Sci. 2, 722-729.

48. Telfer, A., Dhami, S., Bishop, S. M., Phillips, D., and Barber, J. (1994) $\beta$ Carotene quenches singlet oxygen formed by isolated photosystem II reaction centers, Biochemistry 33, 14469-14474.

49. Chung, S. K., and Jung, J. (1995) Inactivation of the acceptor side and degradation of the D1 protein of photosystem II by singlet oxygen photogenerated from the outside, Photochem. Photobiol. 61, 383-389.

50. Yettella, R. R., and Min, D. B. (2008) Quenching Mechanisms and kinetics of trolox and ascorbic acid on the riboflavin-photosensitized oxidation of tryptophan and tyrosine, J. Agric. Food Chem. 56, 10887-10892.

51. Lindig, B. A., and Rodgers, M. A. J. (1981) Rate parameters for the quenching of singlet oxygen by water-soluble and lipid-soluble substrates in aqueous and micellar systems, Photochem. Photobiol. 33, 627-634.

52. Gutierrez, I., Criado, S., Bertolotti, S., and Garcia, N. A. (2001) Dark and photoinduced interactions between Trolox, a polar-solvent-soluble model for vitamin E, and riboflavin, J. Photochem. Photobiol. 62, 133-139. 
1 4

6

53. Fukuzawa, K., Matsuura, K., Tokumura, A., Suzuki, A., and Terao, J. (1997)

Kinetics and dynamics of singlet oxygen scavenging by $\alpha$-tocopherol in phospholipid model membranes, Free Radic. Biol. Med. 22, 923-930.

54. Lúcio, M., Nunes, C., Gaspar, D., Ferreira, H., Lima, J. L. F. C., and Reis, S. (2009) Antioxidant activitity of vitamin E and trolox: Understanding of the factors that govern lipid peroxidation studies in vitro. Food Biophys. 4, 312-320. 
Table 1. Total bimolecular rate constant $\left(k_{\mathrm{t}}\right)$ for the scavenging of ${ }^{1} \mathrm{O}_{2}$ by Trolox in aqueous mixtures.

\begin{tabular}{lcc}
\hline Solvent & $k_{\mathrm{t}}\left(10^{8} \mathrm{M}^{-1} \mathrm{~s}^{-1}\right)$ & Reference \\
\hline $\mathrm{H}_{2} \mathrm{O}$ & 0.13 & $(50)$ \\
$\mathrm{H}_{2} \mathrm{O} / \mathrm{EtOH}(50: 50, \mathrm{v} / \mathrm{v}) \mathrm{pH} 2.0-8.4$ & $0.6-1.0$ & $(25)$ \\
$\mathrm{SDS} / \mathrm{H}_{2} \mathrm{O}, \mathrm{CTAC} / \mathrm{H}_{2} \mathrm{O}$ & 2.2 & This work \\
$\mathrm{DM} / \mathrm{H}_{2} \mathrm{O}$ pH 7.2 & $2.4(1.8)^{*}$ & $(38)$ \\
$\mathrm{D}_{2} \mathrm{O}$ pD 6-12 and pH 6-12 & $3.5-3.6(2.2-6.0)^{*}$ \\
$\mathrm{SDS} / \mathrm{D}_{2} \mathrm{O}, \mathrm{CTAC} / \mathrm{D}_{2} \mathrm{O}$ & $4.0-4.1^{\#}$ \\
$\mathrm{D}_{2} \mathrm{O} / \mathrm{ACN}(50: 50, \mathrm{v} / \mathrm{v})$ & 4.4 & $(24)$ \\
\hline *Chemical rate constant. \#6-hydroxy-2,2,5,7,8-pentamethylchromane. ACN,
\end{tabular}




\section{Figure legends}

Figure 1. Absorption and LD spectra of RC5. (a) Absorption spectra of RC5 in the assay buffer under several treatments: Dark control, black thick solid line; high light treatment under anaerobiosis, dark grey thin line; $1 \mathrm{mM}$ Trolox plus high light treatment under aerobiosis in the assay buffer, blue thin line; $1 \mathrm{mM}$ Trolox plus high light treatment under aerobiosis in $0.01 \%(\mathrm{w} / \mathrm{v}) \mathrm{DM}$, red thin line; high light treatment under aerobiosis, light grey thin line. Treatment time: 2 min. Inset: LD of control RC5 at 77 $\mathrm{K}$, black thick line. For the sake of comparison the LD spectrum of RC6 at $77 \mathrm{~K}$ is included, grey dashed line. (b) Difference absorption spectrum between RC5 treated with 1mM Trolox plus high light under aerobiosis minus dark control RC5 in the assay buffer (blue thin line) and similar difference absorption spectrum when Trolox is dissolved in water containing $0.01 \%$ (w/v) DM (red thin line). Vertical dashed line centered at $675 \mathrm{~nm}$ is added to better visualize the photobleaching of pigments in the $\mathrm{Q}_{\mathrm{y}}$ region.

Figure 2. Endogenous production of ${ }^{1} \mathrm{O}_{2}$ by RC5. Temporal profile (obtained by averaging 1024 traces) and the corresponding residuals of ${ }^{1} \mathrm{O}_{2}$ emission at $1270 \mathrm{~nm}$ in RC5 dispersed in $\mathrm{D}_{2} \mathrm{O}$ without the addition (black trace) and with the addition of $25 \mu \mathrm{M}$ Trolox (grey trace). Absorbance of RC5 (for a path length of $1 \mathrm{~cm}$ ) is 1.0 at $675 \mathrm{~nm}$.

Figure 3. Total and chemical bimolecular rate constants for the scavenging of ${ }^{1} \mathrm{O}_{2}$ by Trolox. (a) Temporal profile (obtained by averaging 512 traces) of the phosphorescence emission at $1270 \mathrm{~nm}$ of ${ }^{1} \mathrm{O}_{2}$ photosensitized by $\mathrm{MB}$ dissolved in the assay buffer 
containing increasing concentrations of Trolox: No addition (black trace), $0.05 \mathrm{mM}$ (dark grey trace), $0.1 \mathrm{mM}$ (grey trace) and $0.2 \mathrm{mM}$ (light grey trace). Inset, SternVolmer analysis for the deactivation of ${ }^{1} \mathrm{O}_{2}$. Absorbance of MB is 1.0 at $665 \mathrm{~nm}$. (b) Oxygen consumption by Trolox (black square) and furfuryl alcohol (black circle) in the oxygen electrode chamber, when ${ }^{1} \mathrm{O}_{2}$ is photosensitized by $\mathrm{MB}$ in the assay buffer. Absorbance of MB is 0.3 at $665 \mathrm{~nm}$. All absorbances refer to a path length of $1 \mathrm{~cm}$.

Figure 4. Oxygen consumption in the Clark-type electrode chamber using RC5 and MB as ${ }^{1} \mathrm{O}_{2}$ photosensitizers, and Trolox, L-histidine and furfuryl alcohol as quenchers of ${ }^{1} \mathrm{O}_{2}$. A light intensity of approximately $2 \mathrm{mE} \mathrm{m}^{-2} \mathrm{~s}^{-1}$ was used in all the assays. (a) Representative traces: trace 1, RC5 in the assay buffer without addition; trace 2 and trace 3, MB and RC5, respectively, in water containing $0.01 \%$ (w/v) DM and $0.5 \mathrm{mM}$ Trolox; trace 4 and trace 5, RC5 and MB in the assay buffer and $0.5 \mathrm{mM}$ Trolox, and trace 6, $\mathrm{MB}$ in $50 \mathrm{mM}$ Tris- $\mathrm{HCl} \mathrm{pH} 7.2$ and $0.5 \mathrm{mM}$ Trolox. RC5 absorbance at $675 \mathrm{~nm}$ was 0.3 for trace 1 and 0.15 for traces 3 and 4 . MB absorbance at $665 \mathrm{~nm}$ was 0.15 . (b) Rate of oxygen consumption in the presence of Trolox (black square), furfuryl alcohol (black triangle) and L-histidine (black rhombus) in the assay buffer, and Trolox (black circle) in water containing $0.01 \%(\mathrm{w} / \mathrm{v}) \mathrm{DM}$. The starting absorbance at $675 \mathrm{~nm}$ for each sample was 0.15 . All absorbances refer to a path length of $1 \mathrm{~cm}$.

Figure 5. Western blot analysis of the D1 (a) and D2 (c) photodamage in RC5 in the presence of several chemical and physical quenchers of ${ }^{1} \mathrm{O}_{2}$. Lane 1, dark control sample; lanes 2 and 3, control sample under aerobiosis and anaerobiosis, respectively; lanes 4 and 5, $1 \mathrm{mM}$ Trolox in the assay buffer and $0.01 \%(\mathrm{w} / \mathrm{v}) \mathrm{DM}$, respectively; lanes 6, $1 \mathrm{mM}$ furfuryl alcohol; lane 7, $1 \mathrm{mM}$ L-histidine; lane 8, $2.5 \mathrm{mM} \mathrm{NaN}_{3}$. All the 
RC5 samples had equal protein loading. The starting absorbance at $675 \mathrm{~nm}$ for each sample was 0.3 . All absorbances refer to a path length of $1 \mathrm{~cm}$. A light intensity of approximately $2 \mathrm{mE} \mathrm{m}^{-2} \mathrm{~s}^{-1}$ was used in all the assays for $2 \mathrm{~min}$. (b) A Coomassie R 250-stained, $6 \mathrm{M}$ urea, $15 \%$ acrylamide gel showing the polypeptide pattern of control RC5 is shown for the sake clarity. HD and D1 $\alpha-$ cyt $_{b 559}$ stand for heterodimer D1/D2 and the adduct of the D1 protein and $\alpha$ subunit of cytochrome $b_{559}$.

Figure 6. Protein oxidation analysis in RC5 using the Millipore OxyBlot ${ }^{\mathrm{TM}}$ kit. Lane 1 and 2, control samples under aerobiosis and anaerobiosis conditions; lanes 3 and 4, 1 $\mathrm{mM}$ Trolox in the assay buffer and $0.01 \%(\mathrm{w} / \mathrm{v}) \mathrm{DM}$, respectively; and lane 5, $2.5 \mathrm{mM}$ $\mathrm{NaN}_{3}$. A light intensity of approximately $2 \mathrm{mE} \mathrm{m}^{-2} \mathrm{~s}^{-1}$ was used in all the assays for 2 min. See the Material and Methods section for further details. The arrows indicate the position of the bands corresponding with the monomeric D1 and D2 proteins (lower arrow) and the heterodimer D1/D2 (upper arrow). 


\section{For Table of Contents Use Only}

Trolox, a water soluble analogue of $\alpha$-tocopherol, photoprotects the surfaceexposed regions of the photosystem II reaction centre in vitro. Is this physiologically relevant? ${ }^{\dagger}$

Juan B. Arellano ${ }^{\ddagger,,^{*}}$, Heng Li ${ }^{\S}$, Sergio González-Pérez ${ }^{\ddagger}$, Jorge Gutiérrez ${ }^{\ddagger}$, Thor Bernt Mel $\varnothing^{\S}$, Frantisek Vachal, K. Razi Naqvi ${ }^{\S}{ }^{\text {** }}$

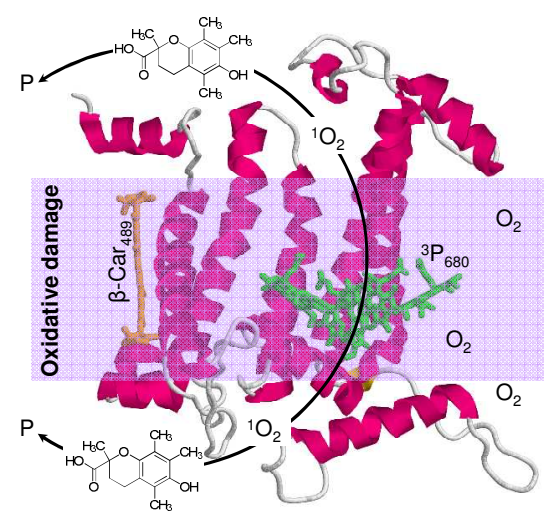




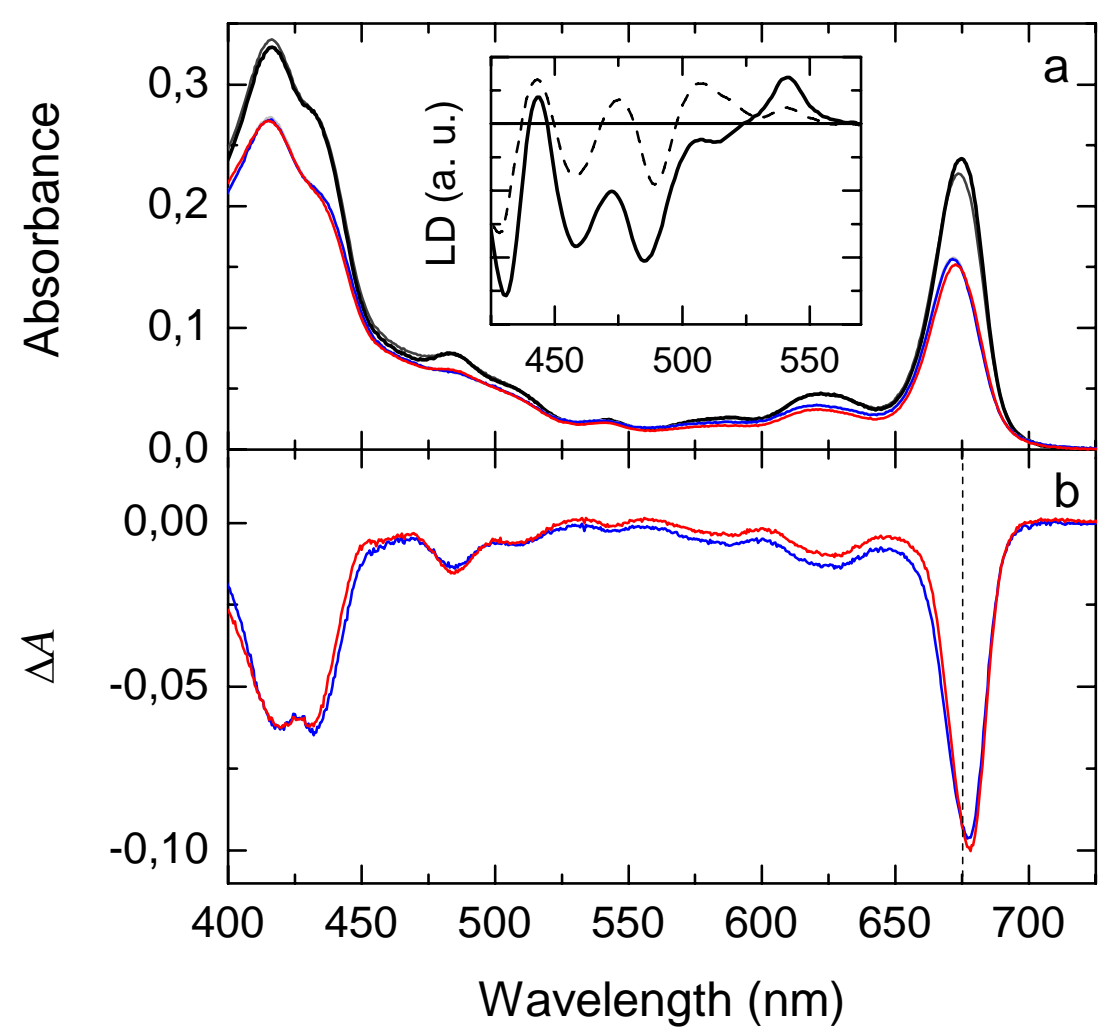


Figure 2

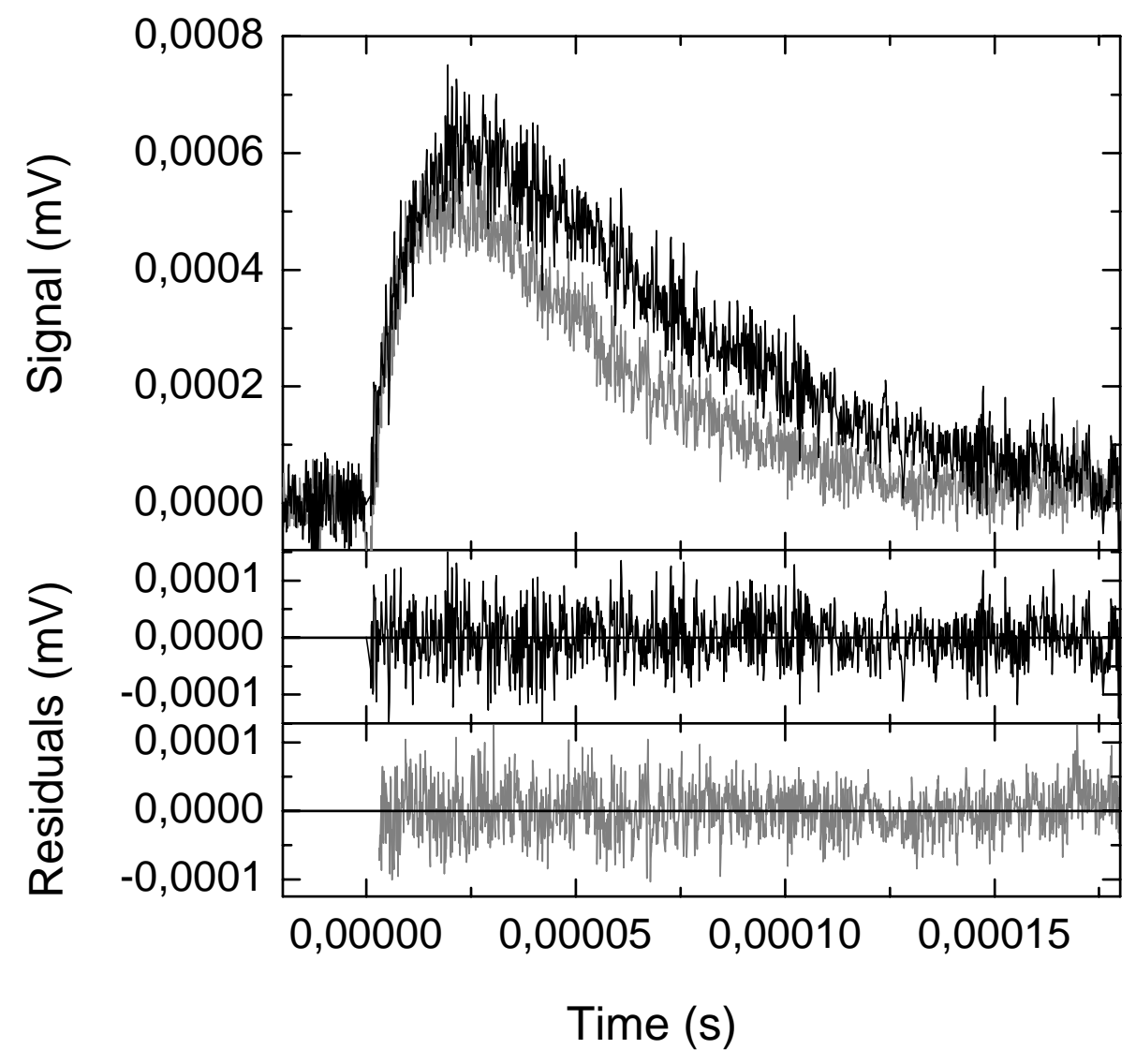



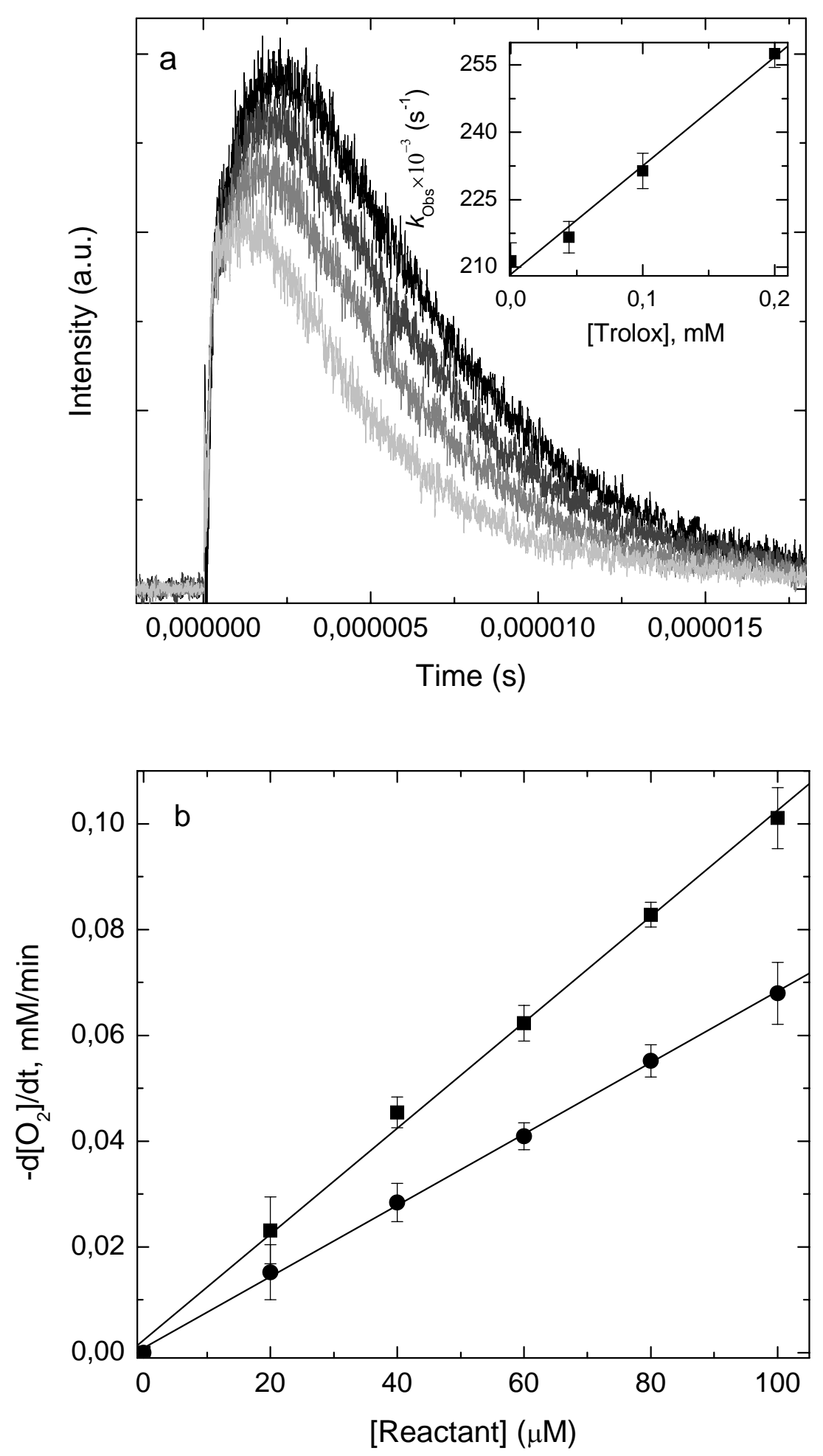
Figure 4
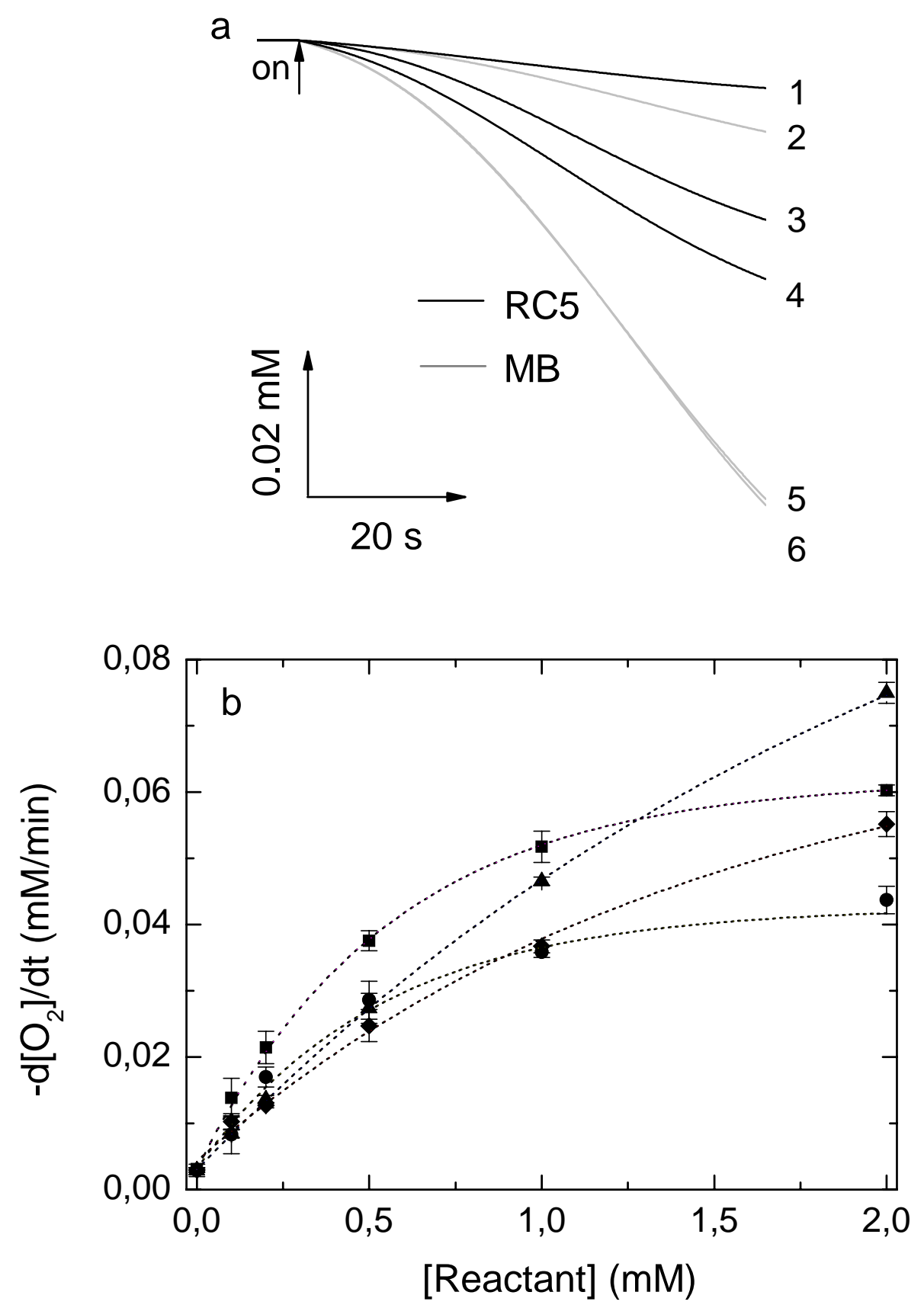
Figure 5

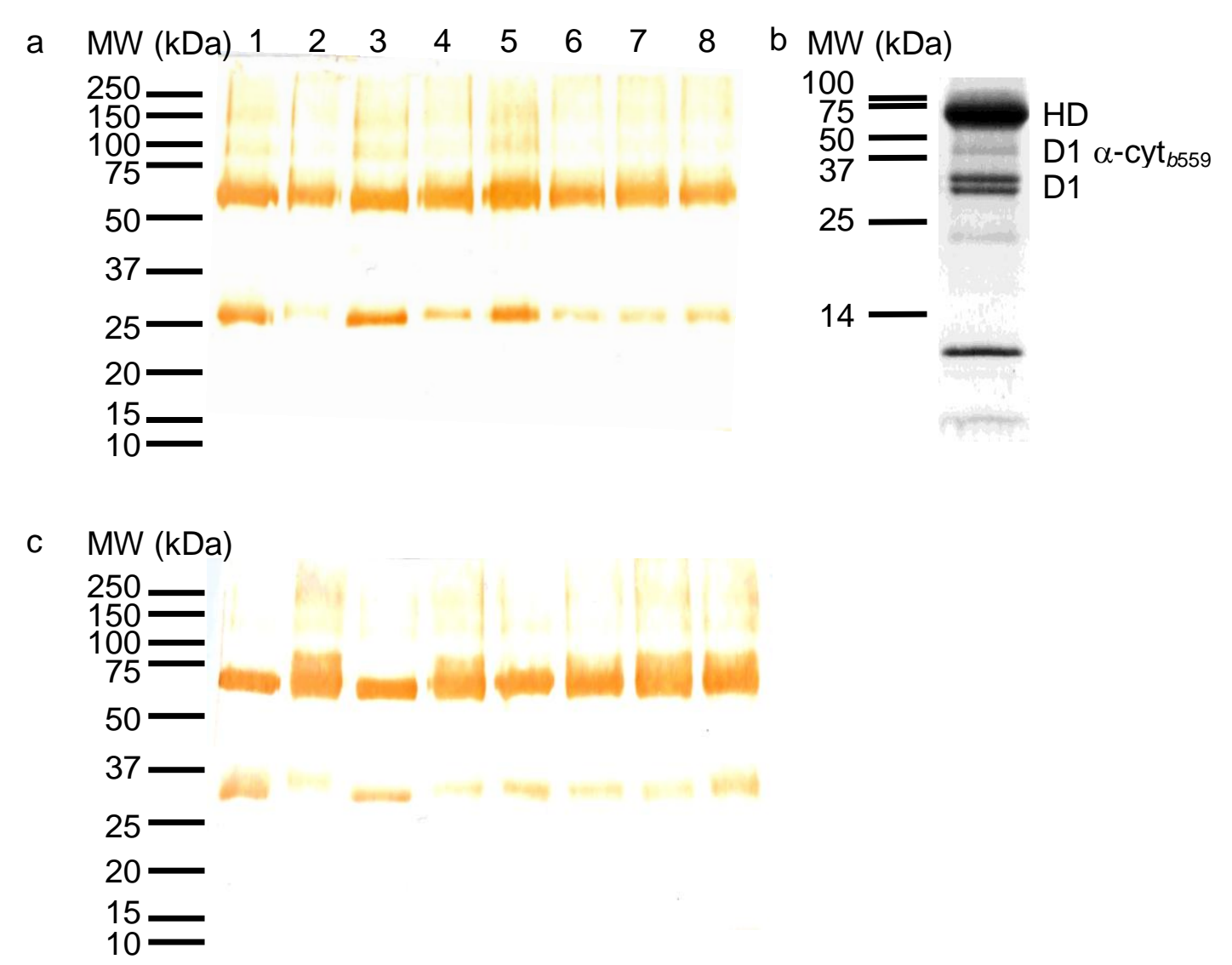


Figure 6

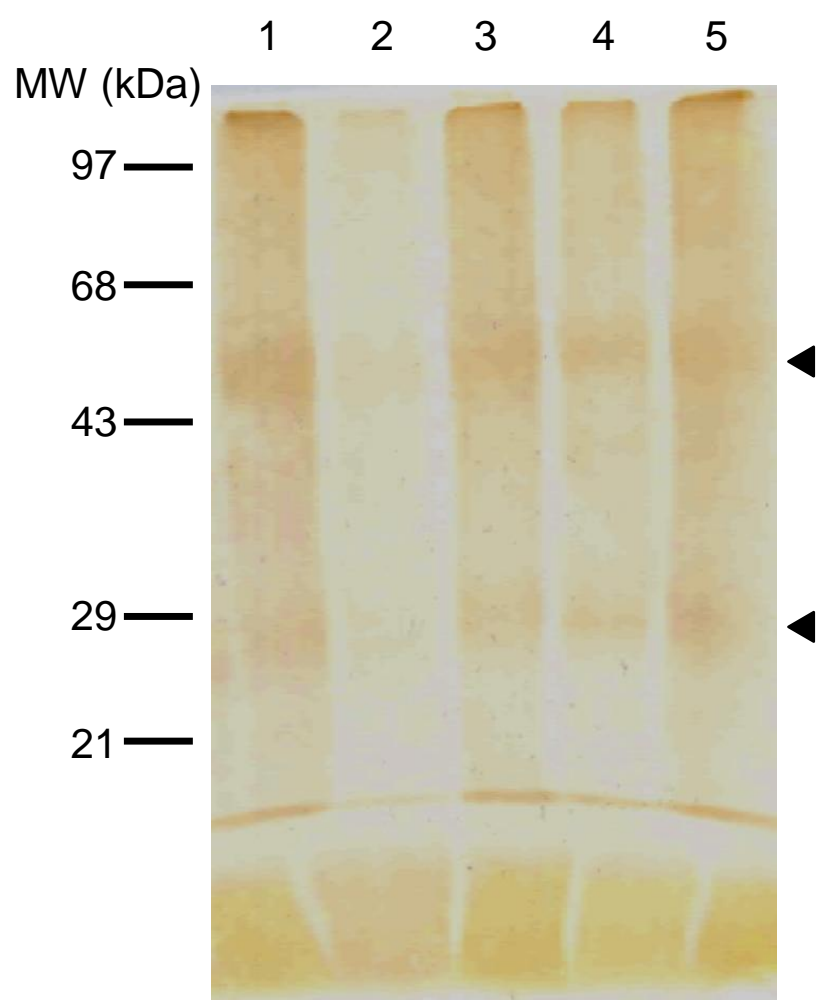

